\title{
Editorial 35
}

\author{
Eric Scerri
}

Published online: 15 September 2010

(c) Springer Science+Business Media B.V. 2010

Sadly I must begin this editorial by announcing the death of two of our distinguished editorial board members. On February 14th, Krishna Vamellapulli, a regular participant at ISPC conferences and a contributor to this journal, passed away in his adopted hometown of Tucson, Arizona. As recently as the 09 ISPC conference Krishna delighted the audience with his gentle and highly informative style of lecturing which included a special workshop on quantum chemistry.

A little later, on March 20th, John Green, a founding editorial board member, passed away in London. John was a physical organic chemist and a distinguished historian of chemistry who was very helpful to me when I was completing my $\mathrm{PhD}$ in the early $1990 \mathrm{~s}$ in London. I believe it was John Green's idea that led us to organize what was essentially the first international conference on the 'new philosophy of chemistry' and held at the Science Museum in London. This meeting took place a short time before Michael Akeroyd's symposium in Ilkley, Yorkshire, an event that quickly led to the formation of our society which has just held its 14 th annual meeting at University College, Oxford. ${ }^{1}$

Turning to other matters, I am happy to announce the addition of two new deputy editors to replace the outgoing editor Carmen Giunta who leaves us after many years of careful reviewing and editorial work. The two incoming editors are Pieter Thyssen from The University of Leuven in Belgium and Jean-Pierre Llored from the Ecole Polytechnique in Paris. This further internationalization of the journal and the society will be consolidated by a workshop which Llored has organized for September 11th at the Ecole Polytechnique. The aim of this meeting will be to bring together the Anglo-American and French approaches to the study of the foundations of chemistry, both of which parties have much to gain from closer collaboration.

\footnotetext{
1 Following the first un-numbered meeting in Ilkley of 1994, the 14 subsequent official ISPC meetings have taken place in Ilkley, UK (1997), Cambridge, UK (1998), Colombia, CS (1999), Poznan (2000), Loughborough, UK (2001), Washington, DC (2002), Tartu (2003), Durham, UK (2004), Knoxville, TN (2005), Dubrovnik (2006), San Francisco (2007), Coburg (2008), Philadelphia (2009), Oxford, UK (2010).
}

E. Scerri $(\bowtie)$

Department of Chemistry and Biochemistry, UCLA, Los Angeles, CA, USA

e-mail: scerri@chem.ucla.edu 
Finally, I am pleased to announce that due to the efforts of Brigitte van Tiggelen and Klaus Ruthenberg, the next ISPC annual meeting will take place between July 30th and August 3rd in Puerto Rico at the same time as the large IUPAC annual meeting. This will doubtless serve to give our society greater visibility and hopefully attract the interest of more mainstream chemists and chemical educators. 